\title{
Photochemical Alkene Isomerization for the Synthesis of Polysubstituted Furans and Pyrroles under Neutral Conditions
}

\begin{abstract}
Johannes C. L. Walker, ${ }^{\text {t[a] }}$ Simon Werrel, ${ }^{t[a]}$ and Timothy J. Donohoe ${ }^{*[a]}$
Abstract: A photochemical approach to polysubstituted heterocycles using UV induced alkene isomerization is described. The method allows for the synthesis of disubstituted furans and pyrroles under mild and neutral conditions and also provides access to a class of trisubstituted furans pertinent to natural product synthesis. The method has broad functional group tolerance and many richly decorated heterocycles have been prepared incorporating functional groups that are unstable under Brønsted and Lewis acidic conditions.

direct excitation of the enone system without the need for a photocatalyst. UV/Vis absorption spectra of both model enone $3 a$ (prepared by cross metathesis of allyl alcohol 1a and enone $\mathbf{2 a}$ in $94 \%$ yield with Hoveyda Grubbs II catalyst, Table 1) and product furan $\mathbf{4} \mathbf{a}^{10}$ were measured in a series of solvents and indicated that neither compound absorbed in the visible region $(>400 \mathrm{~nm})$ Both displayed a $\pi-\pi^{*}$ absorption below $275 \mathrm{~nm}$. While enone 3a displayed an $n-\pi^{*}$ absorption between $275-375 \mathrm{~nm}$, the absorbance of furan $\mathbf{4 a}$ decayed to essentially zero by $350 \mathrm{~nm}$ giving us an opportunity to avoid product degradation (for UV/Vis spectra, see Supporting Information).
\end{abstract}

Recent advances in the application of photochemistry to organic synthesis have been driven by a renewed appreciation of the orthogonal reaction pathways accessible by photochemical excitation. ${ }^{1}$ These provide opportunities for the synthetic chemist to uncover novel disconnections, aiding the preparation of complex molecules in the areas of total synthesis and drug discovery where high levels of chemoselectivity are a necessity. ${ }^{2}$ Aromatic heterocycles are one of the most common fragment classes found within both natural product 3 and active pharmaceutical agents ${ }^{4,5,6}$ and in this context it is surprising that photochemical methods for their de novo synthesis from acyclic precursors remain underdeveloped. ${ }^{7,8}$ Routes to these fragments that harness the power of photochemistry would be of undoubted value.

In a recent research programme, we have become interested in the development of catalytic chemistry to form aromatic heterocyclic compounds ${ }^{9}$ and reported an alkene metathesis route to disubstituted furans (Scheme 1 , middle). ${ }^{10}$ However, the functional group tolerance was limited due to the acidic conditions and elevated temperatures that were required for aromatisation. Building on this work, we wondered whether a photochemical approach, under $\mathrm{pH}$ neutral conditions, would permit the incorporation of acid sensitive functional groups that would not previously have been tolerated.

Building on the seminal report of House, ${ }^{11}$ Alexakis ${ }^{12}$ and Gilmour 13 independently demonstrated the photochemically enabled isomerization reaction of $\alpha-\beta$ unsaturated carbonyls from their more stable $(E)$ geometry to the $(Z)$ isomer in synthetically useful yields (Scheme 1, middle). ${ }^{14,15,16}$ Alexakis and co-workers accessed a photostationary equilibrium between $(E)$ and $(Z)$ enone isomers through direct excitation of the alkene with a mercury lamp, from which the $(Z)$ isomer was isolated in $42 \%$ yield. Gilmour and co-workers successfully effected selective $(E)$ to $(Z)$ acrylate isomerization using (-)-riboflavin as a triplet sensitiser. By exploiting the steric clash between the phenyl and carbonyl substituents of the $(Z)$ isomer they could deconjugate the chromophore and prevent the reverse isomerization.

Turning to our proposed transformation, we recognised that isomerization of $(E) \mathrm{y}$-hydroxy enone intermediate I to (Z)-I should result in spontaneous condensation to furan II (Scheme 1, bottom). The removal of (Z)-I from a photostationary equilibrium should allow for full consumption of $(E)$-I whilst also permitting

[a] Dr J. C. L. Walker, Dr S. Werrel, Prof. Dr T. J. Donohoe, Department of Chemistry, Chemistry Research Laboratory, University of Oxford, Oxford, OX1 3TA (UK)

E-Mail: timothy.donohoe@chem.ox.ac.uk,

t These authors contributed equally.

Supporting information for this article is given via a link at the end of the document.
Biologically Relevant Heterocyclic Compounds

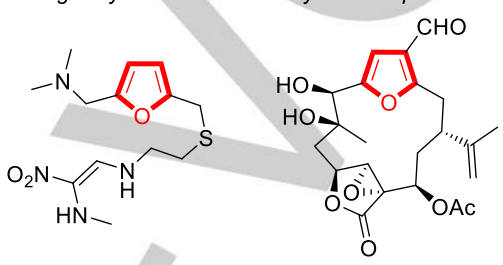

Ranitidine (Zantac) Heartburn Relief
Lophodiol B Antitumour Agent

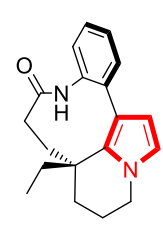

Rhazinilam Anticancer Agent

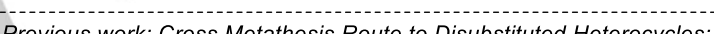
Acid Catalyzed Isomerization via Epoxide/Aziridine

$\mathrm{XH}$

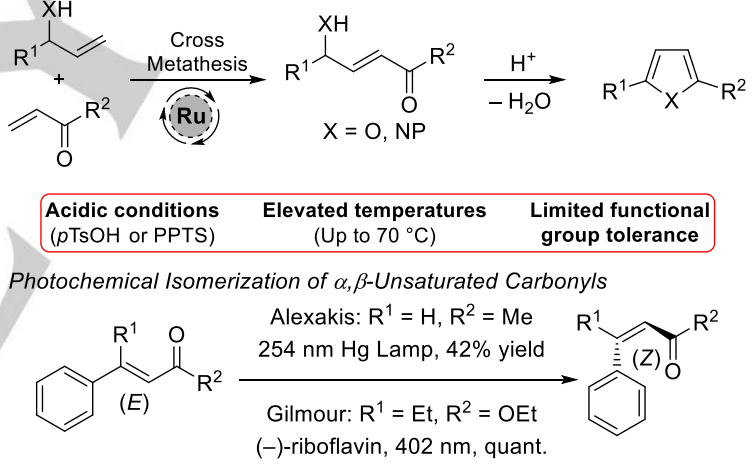

This work: Photochemical Isomerization and Aromatisation to Heterocycles

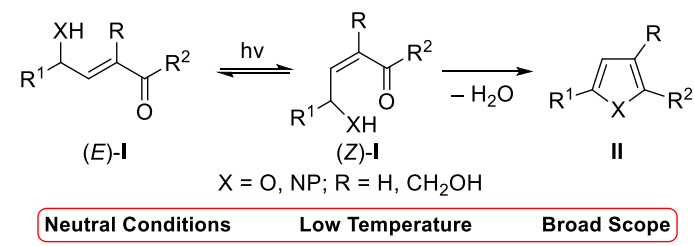

Scheme 1. Importance of heterocyclic compounds and strategies for their synthesis from acyclic precursors.

We therefore elected to use a convenient and commercially available $365 \mathrm{~nm}$ source (Pen-Ray; see ESI for details of the light source used), hoping that the desired isomerization would take place without product degradation. We were delighted to find that irradiation of enone $3 a$ at $365 \mathrm{~nm}$ in diethyl ether at $0{ }^{\circ} \mathrm{C}$ under an air atmosphere led to complete consumption of the starting material within $5 \mathrm{~h}$ and formation of furan $4 \mathrm{a}$ in $67 \%$ yield (Table 1, Entry 1). Careful argon sparging of the solvent and conducting the reaction under an argon atmosphere increased the yield to $85 \%$ (Entry 2). A brief solvent screen revealed that the reaction tended to be higher yielding in less polar solvents (Entries 3-5) although the poor solubility of enone $\mathbf{3 a}$ in cyclohexane led to low conversion (Entry 6). However, a 3:1 mixture of cyclohexane and chloroform provided furan $\mathbf{4 a}$ in near quantitative yield (Entry 
7). Conducting the reaction under otherwise identical conditions but without irradiation led to no reaction (Entry 8) and irradiation in the presence of pyridine had no observable deleterious effect, with full conversion to the furan observed by ${ }^{1} \mathrm{H}$ NMR spectroscopy (Entry 9). This control reaction suggests that any decomposition of the chloroform solvent by UV light to $\mathrm{HCl}$ and subsequent Brønsted acid mediated isomerization is not a contributing reaction pathway. ${ }^{17}$ Full consumption of enone $3 \mathbf{a}$ was observed when conducting the reaction with a $254 \mathrm{~nm}$ source but furan $4 a$ was isolated in only $68 \%$ yield (Entry 10 vs 2). The remainder of the mass balance was made up of decomposition side-products, as expected by the absorbance at this wavelength by the furan product $\mathbf{4 a}$. Pleasingly, the key reaction could also be scaled up to $3.5 \mathrm{mmol}$ with minimal reduction in yield, although a longer reaction time was required (Entry 11$)$.

Table 1 Optimization of Photochemical Isomerization to Disubstituted Furans

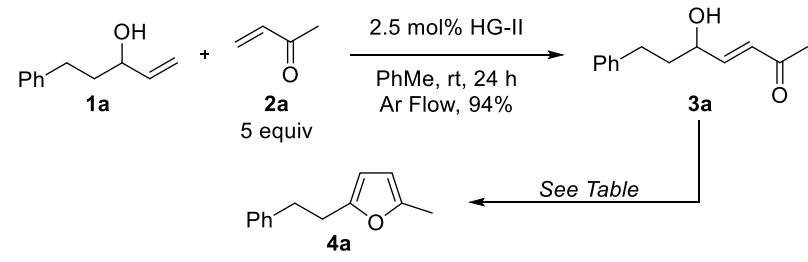

\begin{tabular}{ccccc}
\hline Entry & Solvent & $\begin{array}{c}\text { Time } \\
\text { (h) }\end{array}$ & $\begin{array}{c}\text { Change to }_{\text {Procedure }^{\mathrm{a}}} \\
\text { (\%) }\end{array}$ & $\begin{array}{c}\text { Yield 4a } \\
(\%)\end{array}$ \\
\hline 1 & $\mathrm{Et}_{2} \mathrm{O}$ & 5 & $\begin{array}{c}\text { Solvent not } \\
\text { argon } \\
\text { sparged }\end{array}$ & 67 \\
3 & $\mathrm{Et}_{2} \mathrm{O}$ & 5 & - & 85 \\
4 & $\mathrm{EtOAc}$ & 2 & - & 50 \\
5 & $\mathrm{CH}_{2} \mathrm{Cl}_{2}$ & 2 & - & 88 \\
6 & $\mathrm{PhMe}_{7}$ & 2 & - & 91 \\
7 & $\mathrm{C}_{6} \mathrm{H}_{12}$ & 2 & - & 22 \\
8 & $\mathrm{C}_{6} \mathrm{H}_{12}: \mathrm{CHCl}_{12}: \mathrm{CHCl}_{3}(3: 1)$ & 2 & - & 97 \\
9 & $\mathrm{C}_{6} \mathrm{H}_{12}: \mathrm{CHCl}_{3}(3: 1)$ & 2 & $\begin{array}{c}\text { No } \\
\text { irradiation }\end{array}$ & 0 \\
10 & $\mathrm{Et}_{2} \mathrm{O}$ & 2 & 1 equiv. & Quant. \\
11 & $\mathrm{C}_{6} \mathrm{H}_{12}: \mathrm{CHCl}_{3}(3: 1)$ & 48 & 3.5 mmol & 95
\end{tabular}

aReaction conditions for photochemical isomerization: $0.25 \mathrm{mmol}$ enone $\mathbf{3 a}$, h $(365 \mathrm{~nm}), 0^{\circ} \mathrm{C}$; solvent was sparged with argon for 10 minutes prior to use. Reactions were performed in a quartz glass vessel. ${ }^{\mathrm{b}} \mathrm{By}{ }^{1} \mathrm{H}$ NMR spectroscopy with respect to starting material.

With optimized conditions in hand we explored the scope of the reaction with an emphasis on substrates that would not be tolerated under Brønsted acidic conditions (Scheme 2). ${ }^{10}$ All substrates performed well in the cross metathesis reaction; sterically demanding species (3f) as well as those containing strong donor atoms $(\mathbf{3 c}-\mathbf{d})^{18}$ produced the corresponding enones in high yield. The photochemical irradiation sequence demonstrated excellent functional group tolerance; THP protected alcohols and cyclic acetal protected diols could be incorporated to provide furans $\mathbf{4 b}$ and $\mathbf{4 c}$ in $95 \%$ and $98 \%$ respectively. Boc protected amines were also suitable substrates with furan 4d synthesized in $93 \%$ yield and aryl bromide substituted furan $\mathbf{4 e}$ was formed in $75 \%$ yield. Furan $\mathbf{4 f}$, bearing a sulfone group, was formed in an excellent $95 \%$ yield and primary silyl ethers were also tolerated, as in $\mathbf{4 g}$. Enone $\mathbf{3 h}$ which, rather than aromatising, cyclized to give acetal $5 \mathrm{~h}$ under the previously reported Brønsted acidic conditions, ${ }^{10}$ was now cleanly converted into furan $4 \mathrm{~h}$ in $89 \%$ yield.

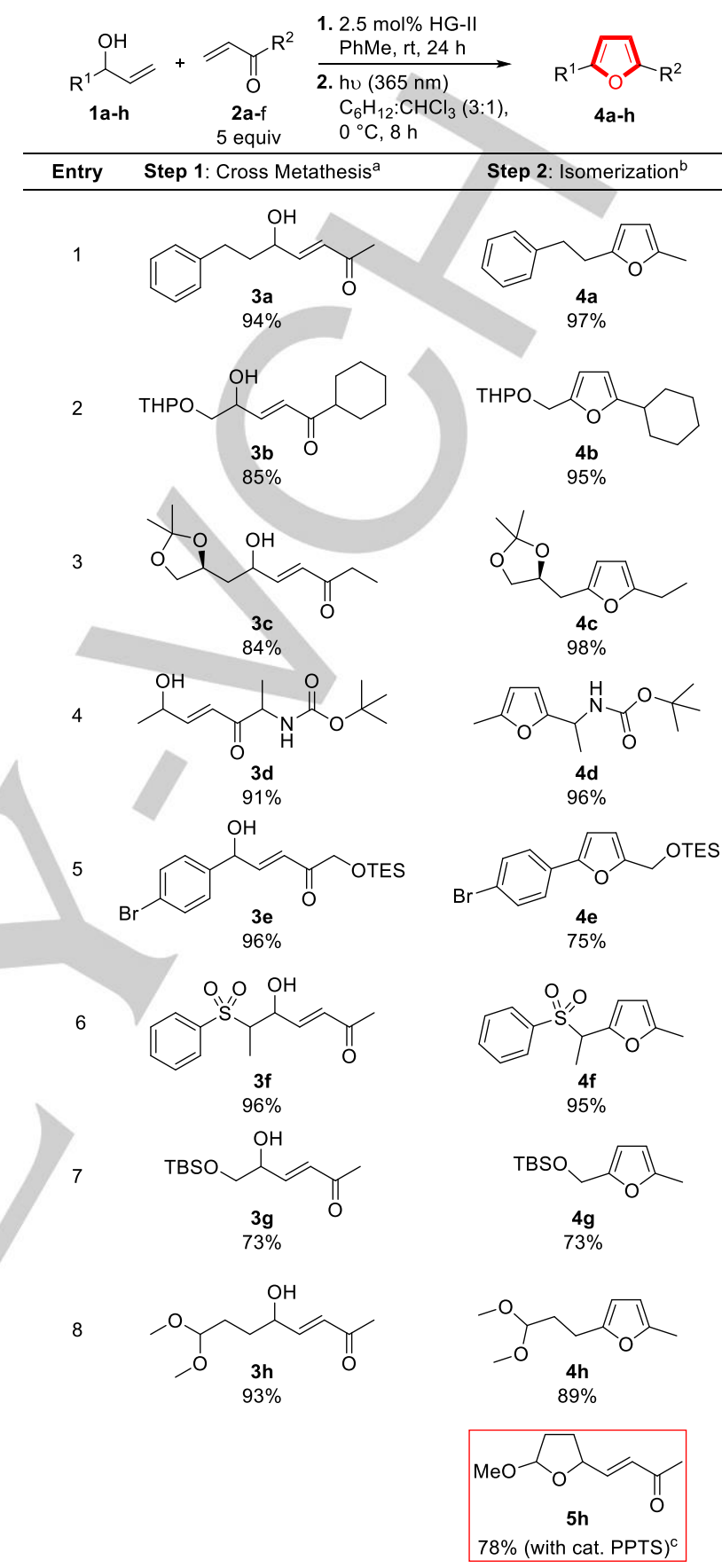

Scheme 2 Scope of disubstituted furan formation. aPerformed on $1.00 \mathrm{mmo}$ scale. ${ }^{b}$ Performed on $0.25 \mathrm{mmol}$ scale. ${ }^{c} 2.5 \mathrm{~mol} \%$ PPTS, $\mathrm{CH}_{2} \mathrm{Cl}_{2}$, rt, 24 h. ${ }^{10}$

Previously, we had shown that $(Z)$ - gamma $N$-Ts enones could be isomerized to pyrroles under strongly acidic conditions at elevated temperatures. ${ }^{19}$ We were therefore keen to establish whether our low temperature UV protocol would also enable access to this widely used class of substrate (Scheme 3). Synthesis of the required $\gamma$-amino enone intermediates by cross metathesis of allyl amines 6 with $\alpha, \beta$-unsaturated enones 2 required slight heating to offset the reduced amine reactivity. ${ }^{20}$ The identity of the amine protecting group had little effect on metathesis reactivity with $\mathrm{Cbz}$ (7a), Boc (7b) and Ts (7c) groups all well tolerated. Subjection of enones $7 a-c$ to our standard irradiation conditions then furnished the corresponding $\mathrm{Cbz}(\mathbf{8 a}, \mathbf{9 1} \%)$, Boc (8b, 88\%), and Tosyl (8c, $40 \%$ ) protected pyrroles. The decomposition of $N$-tosyl protecting groups under photochemical conditions has previously been 
reported by Yonemitsu and co-workers. ${ }^{21}$ Note that increased HG-II catalyst loadings were required to achieve practical cross metathesis yields of sterically demanding enones $\mathbf{7 d}$ and $\mathbf{7 e}$, although in both cases much of the unreacted starting material could also be re-isolated. Cyclic acetal and aryl substituted pyrroles $8 \mathrm{~d}$ and $8 \mathrm{e}$ could then be formed in $67 \%$ and $46 \%$ yield respectively under irradiation.

Entry Step 1: Cross Metathesis ${ }^{\mathrm{a}}$

Scheme 3. Scope of disubstituted pyrrole formation. aperformed on $1.00 \mathrm{mmo}$ scale. ${ }^{b}$ Performed on $0.25 \mathrm{mmol}$ scale. ${ }^{\circ} 44 \%$ 6 d was recovered. ${ }^{d} 39 \% 6$ was recovered.

After these studies showed that the photochemical isomerisation/aromatisation protocol was viable, we decided to investigate application in more substituted examples. Specifically, we are interested in developing routes to trisubstituted furans bearing a single carbon unit at the C-3 position. ${ }^{22}$ These fragments are present in a wide range of natural product targets, including many members of the furanocembranoid family (eg. lophodiol B, Scheme 1). ${ }^{23}$ In this case, we envisaged that cross metathesis between allylic alcohols III and 1,1-disubstituted enones IV would provide $y$-hydroxy enones $\mathbf{V}$ which could then be isomerized (and aromatised) to the desired trisubstituted furans VI (Scheme 4, top). In preliminary work, the direct cross metathesis between the requisite allylic alcohol (1a) and 1,1disubstituted enone (9a) was unsuccessful. Reaction of 1a and 9a together with Hoveyda-Grubbs Second Generation catalyst gave no observable $\mathrm{CM}$ product formation by ${ }^{1} \mathrm{H}$ NMR spectroscopy. Enone variants of 9a lacking the hydroxyl group (ie. with a methyl substituent) or with a TES protected alcohol were also unreactive in cross metathesis (see Supporting Information for further details). The combination of a secondary allylic alcohol and a 1,1-disubstituted deactivated alkene is very challenging for cross metathesis chemistry. However, we were able to overcome the poor reactivity by using a temporary silicon-tether-ring-closing metathesis (TST-RCM) approach, commonly used to access $Z$ alkenes (Scheme 4, bottom). ${ }^{24}$ Synthesis of TST silaketal 10a was straightforward ${ }^{25}$ and ring-closing metathesis resulted in smooth conversion to cyclic silaketal 11a in $88 \%$ yield. Deprotection of the tether using catalytic quantities of TBAF provided diol 12a in $99 \%$ yield. ${ }^{26}$ Despite the additional steps this approach to formal cross metathesis chemistry provides a strategic advantage for complex molecule synthesis as only a small excess of one valuable metathesis partner (1.1 equiv.) is required.

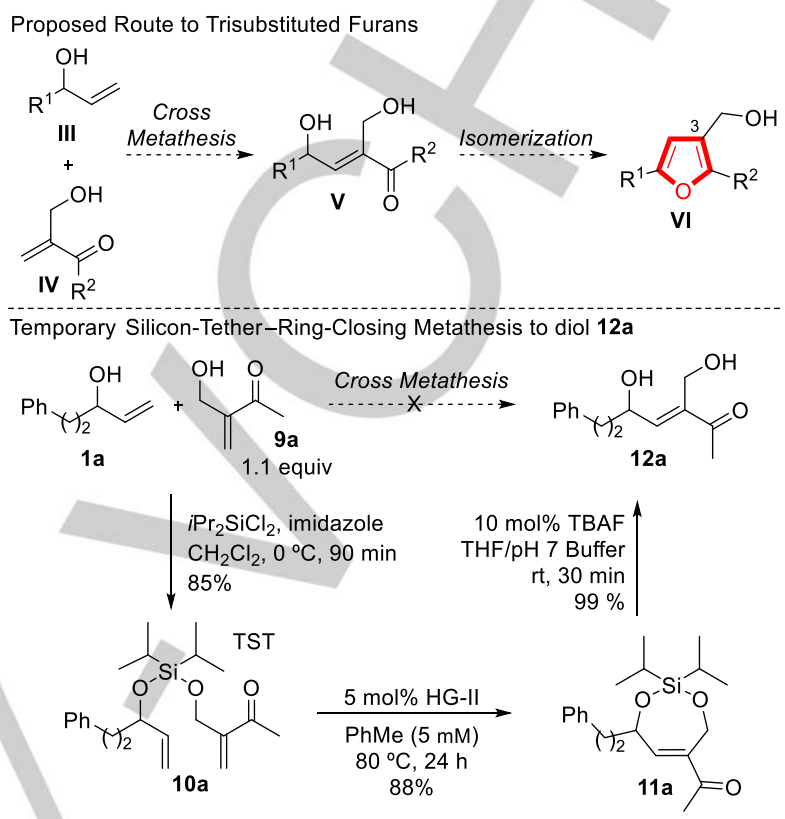

Scheme 4. Alkene metathesis approaches to trisubstituted furans.

Efforts to isomerize and aromatise diol 12a to trisubstituted furan 13a using Brønsted or Lewis acid catalysis were unsuccessful. However, we were delighted to find that, after reoptimization for the new substrate, irradiation of diol 12a at $365 \mathrm{~nm}$ in EtOAc afforded furan 13a cleanly in almost quantitative yield (Scheme 5), demonstrating the ability of the photochemical isomerization to facilitated aromatisation of sensitive substrates under mild conditions, in addition to providing the broad substrate tolerance described earlier.
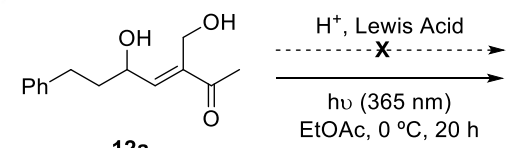
$96 \%$

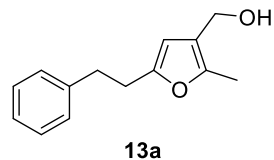

Scheme 5. Isomerization of diol 12a to trisubstituted furan 13a

Given the high value of the products in synthetic chemistry projects, the scope of this approach to trisubstituted furans was then explored (Scheme 6). Formation of the TST metathesis precursors was achieved in uniformally high yield. The efficiency of the subsequent ring-closing metathesis step correlated with the steric demand of the substrates; increased steric bulk adjacent to the secondary allylic alcohol resulted in reduced conversion (see 11c and 11d). Interestingly, diastereoselective ring-closing metathesis was observed when the TST starting material contained two secondary allylic alcohols, giving the syn silaketal $11 \mathrm{e}$ in $45 \%$ (maximum $50 \%$ yield). ${ }^{27}$ Removal of the TST was generally high yielding; only for more hindered silaketal 11e was a lower yield observed. The final photochemical isomerization step then furnished the desired furans directly. Furan 13b, with the C-1 and C-4 substitutents swapped, was formed in $89 \%$ yield and those displaying increased steric hindrance adjacent to the furan (as in 13c and 13d) could also be formed in good to excellent yield. The extended conjugation found in furan $13 \mathrm{c}$ led to a lower isolated yield together with unidentified decomposition side-products. Finally, furan $\mathbf{1 3 e}$, bearing a secondary alcohol at 
C-3, was formed in $67 \%$ yield and furan 13f, bearing a TBS protected alcohol, in $46 \%$ yield.

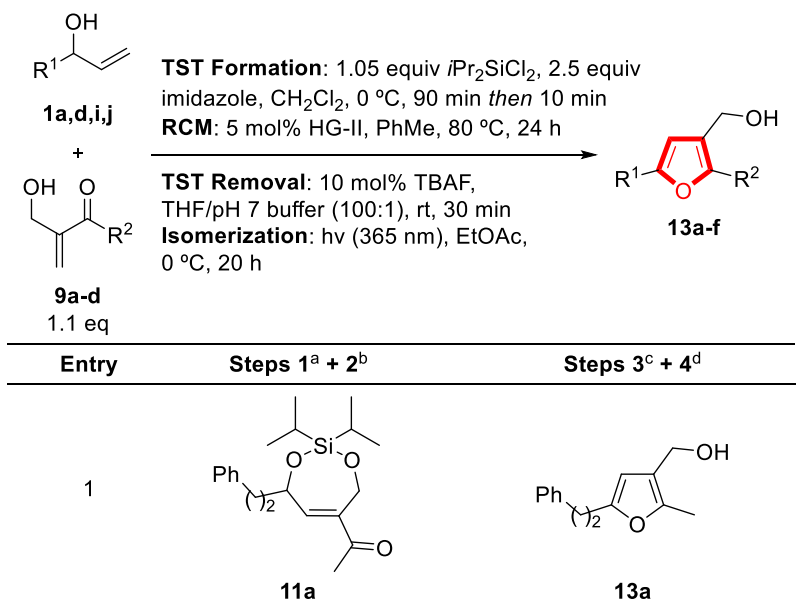

Tether: $78 \%$ RCM: $84 \% \quad$ Deprotection: $99 \%$ UV: $96 \%$<smiles>CC1C=C(C(=O)c2ccccc2)CO[Si](C(C)C)(C(C)C)O1</smiles>

$11 \mathrm{~b}$

Tether: $72 \%{ }^{\mathrm{e}} \mathrm{RCM}$ : $85 \%$

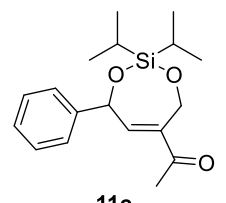

$11 \mathrm{c}$

Tether: $78 \%$ RCM: $48 \%{ }^{\mathrm{f}}$<smiles>CC(=O)C1=CC(C(C)COC(C)(C)C)O[Si](C(C)C)(C(C)C)OC1</smiles>

11d

Tether: $82 \%$ RCM: $35 \%{ }^{9}$<smiles>CC(C)C[C@H]1O[Si](C(C)C)(C(C)C)O[C@H](Pc2ccccc2)C=C1C(=O)O</smiles>

Tether: $77 \%$ RCM: $45 \%{ }^{\text {h }}$

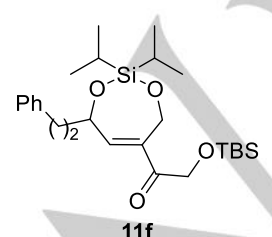

Tether: $94 \%$ RCM: $84 \%$

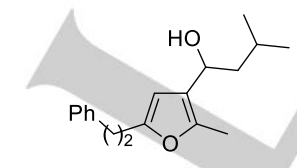

13

Deprotection: $45 \%$ UV: $67 \%$

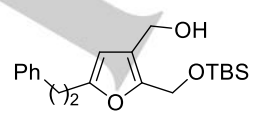

$13 f$

Deprotection: $40 \%$ UV: $46 \%$

Scheme 6. Scope of trisubstituted furan formation. aPerformed on $3.00 \mathrm{mmol}$ scale. berformed on $1.00 \mathrm{mmol}$ scale. ${ }^{\mathrm{b} P e r f o r m e d ~ o n ~} 0.22-0.50 \mathrm{mmol}$ scale. dPerformed on $0.05-0.15 \mathrm{mmol}$ scale. ${ }^{\mathrm{e}} 1.27 \mathrm{mmol}$ scale ${ }^{\dagger} 10 \mathrm{~mol} \%$ HG-II, 100 ${ }^{\circ} \mathrm{C}$. ${ }^{\mathrm{f}} 39 \%$ 10c was recovered. ${ }^{\mathrm{g}} \mathrm{Performed}$ on a $0.877 \mathrm{mmol}$ scale; $54 \% 10 \mathrm{~d}$ was recovered. hkinetic resolution to furnish the cis product.

In conclusion, a photochemical approach to functionalized heterocycles has been developed. The use of UV light in place of Brønsted acids allows for the synthesis of functionally rich disubstituted furans and pyrroles under mild and easily accessible conditions. Additionally, the photochemical route enabled the isomerization of otherwise unreactive diols to give trisubstituted furans. We anticipate that this method will find utility in both drug discovery and natural product synthesis, where there is a significant need for mild new routes to highly functionalised aromatic heterocycles.

\section{Acknowledgements}

We are grateful to the People Programme (Marie Curie Actions) of the European Union's Seventh Framework Programme (FP7/2007-2013) under REA grant agreement $n^{\circ} 316955$ (S.W.) Cancer Research UK (CR-UK grant number C38302/A13012), through an Oxford Cancer Research Center Prize DPhil Studentship (J.C.L.W.).

\section{Conflict of Interest}

The authors declare no conflict of interest

Keywords: Photochemical isomerization, heterocycles, furans, pyrroles, functional group tolerance

[1] a) S. Poplata, A. Tröster, Y.-Q. Zou, T. Bach, Chem. Rev. 2016, 116 9748-9815; b) K. L. Skubi, T. R. Blum, T. P. Yoon, Chem. Rev. 2016, 116, 10035-10074; c) N. A. Romero, D. A. Nicewicz, Chem. Rev. 2016, 116, 1007510166.

[2] M. D. Kärkäs; J. A. Porco Jr.; C. R. J. Stephenson, Chem. Rev. 2016 116, 9683-9747.

[3] Heterocycles in Natural Product Synthesis, (Eds: K. C. Majumdar, S. K. Chattopaghyay), Wiley-VCH, Weinheim, Germany 2011.

[4] Heterocycles in Drug Discovery, (Ed: J. J. Li), John Wiley and Sons, Hoboken, USA 2013.

[5] For highlighted examples, see: a) R. Wright, J. Health Care Market. 1996 16, 24-29; b) M. Carmen Sánchez, M. J. Ortega, Eva Zubía, J. Luis Craballo, J. Nat. Prod. 2006, 69, 1749-1755; c) H. H. A. Linde, Helv. Chim. Acta 1965, 48, 1822-1842; d) O. Baudoin, D. Guénard, F. Guéritte, Mini-Rev. Org. Chem., 2004, 1, 333-341.

[6] For reviews of routes to substituted furan and pyrrole heterocycles, see: a) J. A. Joule, K. Mills, Heterocyclic Chemistry 5th Ed.; Wiley \& Sons, Chichester 2010; b) W. J. Moran, A. Rodríguez, New J. Org. Synth. 2012, 44, 103-130; c) F. J. Leeper, J. M. Kelly, New J. Org. Synth. 2013, 45, 171-210; d) V. Estévez, M. Villacampa, J. Carlos Menéndez, Chem. Soc. Rev. 2014, 43, 4633-4657.

[7] a) T. Horaguchi, N. Hosokawa, K. Tanemura, T. Suzuki, J. Heterocyclic Chem. 2002, 39, 61-67; b) A. Padwa, T. Stengel, Tetrahedron Lett. 2004, 45 , 5991-5993; c) M. Austin, O. J. Egan, R. Tully, A. C. Pratt, Org. Biomol. Chem 2007, 5, 3778-3786; d) T. Mitamura, A. Ogawa, J. Org. Chem. 2011, 76, 11631166; e) K. Selvam, M. Swaminathan, RSC Advances 2012, 2, 2848-2855; f) J.-R., Chen, X.-Q. Hu, L.-Q. Lu, W.-J. Xiao, Acc. Chem. Res. 2016, 49, $1911-$ 1923

[8] For rearrangements of cyclic species to aromatic heterocyles including furans and pyrroles, see: N. Vivona, S. Buscemi, I. Pibiri, A. P. Piccionello, A Pace, in Handbook of Synthetic Photochemistry, (Eds. A. Albini, M. Fagnoni), Wiley-VCH, Weinheim, Germany 2010, pp. 387-416.

[9] a) T. J. Donohoe, J. F. Bower, L. K. M. Chan, Org. Biomol. Chem. 2012 10, 1322-1328; b) H. K. Potukuchi, A. P. Spork, T. J. Donohoe, Org. Biomol. Chem. 2015, 13, 4367-4373; c) B. S. Pilgrim, A. E. Gatland, C. H. A. Esteves, C. T. McTernan, G. R. Jones, M. R. Tatton, P. A. Procopiou, T. J. Donohoe, Org. Biomol. Chem. 2016, 14, 1065-1090.

[10] a) T. J. Donohoe, J. F. Bower, Proc. Natl. Acad. Sci. US. 2010, 107 3373-3376; b) T. J. Donohoe, J. F. Bower, J. A. Basutto, Nature Protocols 2010 5, 2005-2010.

[11] H. O. House, J. Org. Chem. 1959, 24, 1374-1375.

[12] M. Vuagnoux-d'Augustin, A. Alexakis, Eur. J. Org. Chem. 2007, 35, $5852-5860$

[13] a) J. B. Metternich, R. Gilmour, J. Am. Chem. Soc. 2015, 137, 11254 11257 ; b) J. B. Metternich, R. Gilmour, Synlett 2016, 27, 2541-2552.

[14] For other reports of $(E)$ to $(Z)$ alkene isomerization including examples of enones, see: a) D. C. Farby, M. A. Ronge, M. Rueping, Chem. Eur. J. 2015 21, 5350-5354; b) A Singh, C. J. Fennel, J. D. Weaver, Chem. Sci. 2016, 7, 6796-6802; c) W. Cai, H. Fan, D. Ding, Y. Zhang, W. Wang, Chem. Comm. 2017, 53, 12918-12921.

[15] J. B. Metternich, R. Gilmour, J. Am. Chem. Soc. 2016, 138, 1040-1045 [16] For a recently disclosed related transition metal catalysed approach, see: K. Zhan, Y. Li, Catalysts 2017, 7, 337-345.

[17] D. M. Sammond, T. Sammakia, Tetrahedron Lett. 1996, 37, 60656068 .

[18] a) A. Fürstner, K. Langemann, Synthesis 1997, 792-803; b) $S$. BouzBouz, J. Cossy, Org. Lett. 2001, 3, 1451-1454.

[19] T. J. Donohoe, N. J. Race, J. F. Bower, C. K. A. Callens, Org. Lett. 2010, $12,4094-4097$. 
[20] a) P. Compain, Adv. Synth. Catal. 2007, 349, 1829-1846; b) B. J. Ireland, B. T. Dobigny, D. E. Fogg, ACS Catal. 2015, 5, 4690-4698.

[21] T. Hamada, A. Nishida, O. Yonemitsu, J. Am. Chem. Soc. 1986, 108 $140-145$.

[22] For previous approaches to trisubstituted furans pertinent to furanocembranoid synthesis, see: a) P. Wipf, L. T. Rahman, S. R. Rector, J. Org. Chem. 1998, 63, 7132-7133; b) J. S. Clark, A. Boyer, A. Aimon, P. E. García, D. M. Lindsay, A. D. F. Symington, Y. Danoy, Angew. Chem. Int. Ed. 2012, 51, 12128-12131; Angew. Chem. 2012, 124, 12294-12297; c) H. Zhan X. Lin, Y. Qiu, Z. Du, P. Li, Y. Li, H. Cao, Eur. J. Org. Chem. 2013, 12, 2284 2287; d) T. Wang, S. Shi, M. H. Hansmann, E. Rettenmeier, M. Rudolph, A. S. K. Hashmi, Angew. Chem. Int. Ed. 2014, 53, 3715-3719; Angew. Chem. 2014 126, 3789-3793.

[23] For examples, see: a) M. Ochi, K. Yamada, H. Kawakami, A. Tatsukawa, H. Kotsuki, K. Shibata, Tetrahedron Lett. 1992, 33, 7531-7534; b) P. A. Roelthe, D. Trauner, Nat. Prod. Rep. 2008, 25, 298-317; c) K. Kojima, T. Ohno, M, Inoue, H. Mizukami, A. Nagatsu, Chem. Pharm. Bull. 2008, 56, 173-175; d) J. Wu, S. Zhang, T. Bruhn, Q. Xiao, H. Ding, G. Bringmann, Chem. Eur. J. 2008, 14 1129-1144; e) A. U. Rao, D. Xiao, X. Huang, W. Zhou, J. Fossetta, D. Lundell, F. Tian, P. Trivedi, R. Aslanian, A. Palania, Bioorg. Med. Chem. Lett. 2012, 22, 1068-1072; f) T. Liu, J. Zhu, S.-Y. Zhang, Z.-L. Li, L.-P. Guan, H.-Q. Pan, X Wu, J. Bai, H.-M. Hua, Molecules 2013, 18, 15126-15133.

[24] a) S, Bracegirdle, E. A. Anderson, Chem. Soc. Rev. 2010, 39, 4114 4129; b) A. Čusak, Chem. Eur. J. 2012, 19, 5800-5842.

[25] I. Paterson, D. Gottschling, D. Menche, Chem. Comm. 2005, 28, 35683570.

[26] A. M. DiLauro, W. Seo, S. T. Phillips, S. T.; J. Org. Chem. 2011, 76 7352-7358.

[27] P. A. Evans, J. Cui, G. P. Buffone, Angew. Chem. Int. Ed. 2003, 42, 1734-1737; Angew. Chem. 2003, 115, 1776-1779. 


\section{Entry for the Table of Contents}

\section{COMMUNICATION}

A photochemical approach to polysubstituted heterocycles using UV induced alkene isomerization is described. The method allows for the synthesis of disubstituted furans and pyrroles under mild and neutral conditions and also provides access to a class of trisubstituted furans pertinent to natural product synthesis.

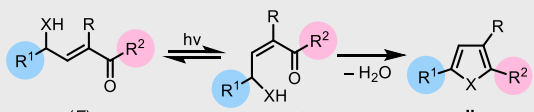

$$
\begin{aligned}
& \text { (E) } \quad \mathrm{X}=\mathrm{O}, \mathrm{NP} ; \mathrm{R}=\stackrel{(\mathrm{Z})}{\mathrm{H}}, \mathrm{CH}_{2} \mathrm{OH} \\
& \text { Neutral Conditions Low Temperature Broad Scope }
\end{aligned}
$$

J. C. L. Walker, S. Werrel and T. J. Donohoe*

\section{Page No. - Page No.}

Photochemical isomerization and aromatization to heterocycles 